Editorial

\title{
Current Status of Stellate Ganglion Block for the Management of Cerebral Vasospasm
}

\author{
Girija Prasad Rath ${ }^{1} \quad$ Ritesh Lamsal ${ }^{1}$ \\ ${ }^{1}$ Department of Neuroanaesthesiology and Critical Care, All India \\ Institute of Medical Sciences (AlIMS), New Delhi, India
}

J Neuroanaesthesiol Crit Care 2018;5:131-132

Delayed cerebral ischemia (DCI) is an important cause of mortality and long-term morbidity in patients with aneurysmal subarachnoid hemorrhage (aSAH). Historically, cerebral vasospasm was considered as the only major underlying pathology leading to cerebral ischemia and infarct in these patients. Several attempts to mitigate the effect of vascular spasm have been made in the form of oral, ${ }^{1}$ intravenous, ${ }^{2}$ and intra-arterial nimodipine, ${ }^{3}$ intra-arterial papaverine, ${ }^{4}$ intrathecal drugs, ${ }^{5}$ hemodynamic augmentation, ${ }^{6}$ pharmacologic sympatholysis, ${ }^{7}$ and various intra-arterial catheter-based techniques. ${ }^{8}$ However, we now understand that the pathophysiology of DCI is complex, and vasospasm is only one of many contributing pathologies.

The cerebral vessels are innervated by noradrenergic sympathetic nerves that constrict these vessels on stimulation, forming the basis of pharmacologic sympatholysis to reverse the effects of vasospasm. The stellate ganglion block (SGB) is the most popular technique to achieve pharmacologic sympatholysis in established vasospasm. The technique of SGB has evolved over the years from being a landmark-based, blind procedure to fluoroscopic-guided, and more recently, ultrasound-guided. The use of the ultrasound has become ubiquitous in the intensive care units (ICUs), and intensivists are becoming increasingly adept at ultrasound techniques for several clinical applications. The appearance of Horner's syndrome is described as an indicator of successful cervical sympathetic block. However, even in experienced hands, it is not possible to reliably block the stellate ganglion in every patient using blind percutaneous techniques. Use of ultrasound technique facilitates accurate deposition of local anesthetic at the desired site, reduces the required volume of the anesthetic, and prevents procedure-related complications, such as inadvertent vascular, neural, pleural, and other soft tissue injury. Moreover, anatomic variations exist in the formation of the stellate ganglion from one person to another. Hence, it is difficult to justify the use of the blind technique for SGB in modern ICUs.
Since Tregiarri et al ${ }^{7}$ first reported improved outcome with cervical ganglion block using bupivacaine and clonidine in patients with angiographically confirmed vasospasm, several similar attempts have been made and reported. Gupta et $\mathrm{al}^{9}$ reported a significant increase in estimated cerebral perfusion pressure and decrease in zero-flow pressure (a surrogate of vascular tone), without any deleterious effect on cerebral autoregulation with SGB, using $2 \%$ lidocaine in patients with complex regional pain syndromes of upper limbs. There are several case reports documenting the utility of SGB in reducing vasospasm related to both anterior and posterior circulation aneurysms. ${ }^{10,11}$ Jain et $\mathrm{al}^{12}$ found improvement in Glasgow coma score, significant reduction in ipsilateral middle cerebral artery flow velocity, and reduction in neurologic deficits after SGB in patients who had established vasospasm following surgical clipping of aneurysm. However, all these studies have reported their findings based on a small number of patients. None of these underpowered studies have enrolled more than 20 patients raising serious questions about the statistical implications of the study results.

The sympathetic nervous system is a potent modulator of vascular tone in peripheral vessels, but the effect of sympathetic stimulation on cerebral vasculature remains a matter of debate in both human and animal-based models, with many studies reporting contradictory results. Magnetic resonance angiography in healthy volunteers after SGB has shown variable effects on extra- and intracranial blood vessels. ${ }^{13}$ Some studies have shown a significant increase in the caliber of intracranial major vessels, while others have failed to demonstrate meaningful reduction in cerebral blood flow velocity after SGB. ${ }^{14-16}$

From the viewpoint of pharmacodynamics, it seems prudent to assume that any maneuver that causes cerebral vasodilatation should reverse the detrimental effect of vasospasm, at least to some degree. However, other than inducing hypertension and administration of nimodipine, no other pharmacologic measure has conclusively proven

\author{
Address for correspondence \\ Girija P. Rath, MD, DM, Department \\ of Neuroanaesthesiology and \\ Critical Care, Neurosciences \\ Centre, All India Institute of \\ Medical Sciences (AIIMS), \\ New Delhi-110029, India \\ (e-mail: girijarath@yahoo.co.in).
}

DOI https://doi.org/ $10.1055 / \mathrm{s}-0038-1675439$ ISSN 2348-0548.
Copyright @2018 Indian Society of Neuroanaesthesiology and Critical Care
License terms

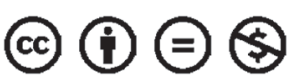


to ameliorate the long-term neurologic outcome in patients with established vasospasm. Even nimodipine is believed to exert its beneficial effect possibly by neuroprotective mechanisms and not due to its vasodilatory properties. ${ }^{17}$ This highlights the pathophysiologic complexities of managing DCI, and that an interaction of incompletely understood distal cellular events, such as inflammation and leucocyte infiltration, microthrombosis, free-radical injury, cortical spreading depolarization, endothelial proliferation, and cellular apoptosis, have a pivotal role in determining the overall neurologic outcome. Studies in animal models suggest that in addition to cerebral vasodilatation, SGB can exert its beneficial effects by altering the expression of several proteins in the brain and promoting antiapoptotic signaling. ${ }^{18}$

Delayed cerebral ischemia is a dreaded complication of aSAH, which can leave the patient with crippling complications and poses a huge burden on the health care delivery system. There are several ongoing studies using protein kinases, sildenafil citrate, newer nitric oxide progenitors, and intracisternal instillation of various drugs, but as of now, lack of high-quality evidence has left the physician with very few tools for successfully managing DCI. SGB emerged as a promising bed-side intervention for managing refractory vasospasm nearly two decades back but has seemingly fallen out of favor in the recent past. The recent combined guidelines from the American Heart Association and the American Stroke Association for the management of aSAH provided no recommendation on the use of SGB for vasospasm. ${ }^{17}$ There may be some justification in the recent loss of popularity of SGB but the lack of an adequately powered randomized study on its utility in treating DCI is glaring. SGB continues to be practiced in some centers around the world. Anecdotal mention of SGB in some recent literature encourages the debate on its role as an adjunct to standard therapy for cerebral vasospasm, albeit, with a strong need for further evaluation.

\section{Conflict of Interest}

None.

\section{References}

1 Pickard JD, Murray GD, Illingworth R, et al. Effect of oral nimodipine on cerebral infarction and outcome after subarachnoid haemorrhage: British aneurysm nimodipine trial. BMJ 1989;298(6674):636-642

2 Seiler RW, Grolimund P, Zurbruegg HR. Evaluation of the calcium-antagonist nimodipine for the prevention of vasospasm after aneurysmal subarachnoid haemorrhage. A prospective transcranial Doppler ultrasound study. Acta Neurochir (Wien) 1987;85(1,2):7-16

3 Kim JH, Park IS, Park KB, Kang DH, Hwang SH. Intraarterial nimodipine infusion to treat symptomatic cerebral vasospasm after aneurysmal subarachnoid hemorrhage. J Korean Neurosurg Soc 2009;46(3):239-244
4 Milburn JM, Moran CJ, Cross DT III, Diringer MN, Pilgram TK, Dacey RG Jr. Increase in diameters of vasospastic intracranial arteries by intraarterial papaverine administration. J Neurosurg 1998;88(1):38-42

5 Ogata M, Marshall BM, Lougheed WM. Observations on the effects of intrathecal papaverine in experimental vasospasm. J Neurosurg 1973;38(1):20-25

6 Origitano TC, Wascher TM, Reichman OH, Anderson DE. Sustained increased cerebral blood flow with prophylactic hypertensive hypervolemic hemodilution ("triple- $\mathrm{H}$ " therapy) after subarachnoid hemorrhage. Neurosurgery 1990;27(5):729-739, discussion 739-740

7 Treggiari MM, Romand JA, Martin JB, Reverdin A, Rüfenacht DA, de Tribolet N. Cervical sympathetic block to reverse delayed ischemic neurological deficits after aneurysmal subarachnoid hemorrhage. Stroke 2003;34(4):961-967

8 John S, Spiotta AM, Turner RM, Chaudry MI, Turk AS, Hui F. Initial experience with the coaxial dual-lumen Scepter $C$ balloon catheter for endovascular management of cerebral vasospasm from subarachnoid hemorrhage. J Neurointerv Surg 2014;6(2):125-128

9 Gupta MM, Bithal PK, Dash HH, Chaturvedi A, Mahajan RP. Effects of stellate ganglion block on cerebral haemodynamics as assessed by transcranial Doppler ultrasonography. Br J Anaesth 2005;95(5):669-673

10 Prabhakar H, Jain V, Rath GP, Bithal PK, Dash HH. Stellate ganglion block as alternative to intrathecal papaverine in relieving vasospasm due to subarachnoid hemorrhage. Anesth Analg 2007;104(5):1311-1312

11 Bindra A, Prabhakar H, Singh GP. Stellate ganglion block for relieving vasospasms after coil embolization of basilar tip aneurysms. J Neurosurg Anesthesiol 2011;23(4):379

12 Jain V, Rath GP, Dash HH, Bithal PK, Chouhan RS, Suri A. Stellate ganglion block for treatment of cerebral vasospasm in patients with aneurysmal subarachnoid hemorrhage-A preliminary study. J Anaesthesiol Clin Pharmacol 2011;27(4):516-521

13 Kang CK, Oh ST, Chung RK, et al. Effect of stellate ganglion block on the cerebrovascular system magnetic resonance angiography study. Anesthesiology 2010;113(4):936-944

14 Nie Y, Song R, Chen W, Qin Z, Zhang J, Tang J. Effects of stellate ganglion block on cerebrovascular vasodilation in elderly patients and patients with subarachnoid haemorrhage. Br J Anaesth 2016;117(1):131-132

15 Ohta S, Hadeishi H, Suzuki M. Effect of stellate ganglion block on cerebral blood flow in normoxemic and hyperoxemic states. J Neurosurg Anesthesiol 1990;2(4):272-279

16 Yokoyama K, Kishida T, Sugiyama K. Stellate ganglion block and regional cerebral blood volume and oxygenation. Can J Anaesth 2004;51(5):515-516

17 Connolly ES Jr, Rabinstein AA, Carhuapoma JR, et al; American Heart Association Stroke Council; Council on Cardiovascular Radiology and Intervention; Council on Cardiovascular Nursing; Council on Cardiovascular Surgery and Anesthesia; Council on Clinical Cardiology. Guidelines for the management of aneurysmal subarachnoid hemorrhage: a guideline for healthcare professionals from the American Heart Association/ American Stroke Association. Stroke 2012;43(6):1711-1737

$18 \mathrm{Hu}$ N, Wu Y, Chen BZ, Han JF, Zhou MT. Protective effect of stellate ganglion block on delayed cerebral vasospasm in an experimental rat model of subarachnoid hemorrhage. Brain Res 2014;1585:63-71 